\title{
PROCESSING OF CONCEPTUAL RELATIONSHIPS WITHIN SIMPLE CZECH AND ENGLISH SENTENCES - ERPS AND BEHAVIORAL CORRELATES
}

\author{
Josef Petrek
}

\author{
Institute of Physiology, Faculty of Medicine, Palacký University, Hněvotínská 3, 77515 Olomouc, Czech Republic \\ e-mail:fesoj@tunw.upol.cz
}

Received: March 20, 2006; Accepted: April 15, 2006

Key words: Language/Czech-English bilinguals/Sentences/Linguistic violations/ERPs/N400/P600/Decision time/ Personality traits

The paper presents findings of an experiment the participants of which were native Czech speakers (L1) possessed of perfect knowledge of English (L2). We assumed that the subjects could process differently each of the three types of English and Czech sentences; the first type represented correct sentences, the other two violated sentences. Violated sentences differed in the precise relationship between the verbs, their preceding noun phrases, and their preceding context. ERPs to critical verbs, the accuracy rate for both English and Czech sentences processing and decision time for each were evaluated. Participants' personality traits were assessed too. It has been shown that our subjects, who learned English after the age of 15, displayed significant differences in all measured parameters. It was especially the longer latency N400, the lower accuracy rate of English sentence processing, the longer decision time, and the same dynamics of all measured ERPs parameters. Possible causes of these differences are discussed.

\section{INTRODUCTION}

Kutas \& Hillyard ${ }^{33}$ were the first to discover in a sentence reading task that semantically inappropriate words in sentences elicit a specific type of event-related brain potential (ERPs). Since, especially over the last decade of the past century and at the beginning of this one, there has been a proliferation of ERPs studies of language processing $2,3,10,13-19,21,23-25,31,34,35,8,39,47,48,50,55$. Numerous are also the papers dealing with different aspects of language processing in bilinguals $1,7,9,22,26,28,30,36,37,45,49,51,54$. Each paper has brought valuable information helping clarify the way the brain comprehends language.

Event-related potentials are currently considered a good tool for studying the cognitive processes which underlie language comprehension. Over the last few decades, at least three specific language-related ERP waves have been identified and analysed - these are N400, LAN and $\mathrm{P} 600$.

The N400 is a large negative wave peaking around $400 \mathrm{~ms}$ after the onset of contextually inappropriate words within sentences. It is believed that the N400 component represents a sensitive indicator of the semantic relationship between a word and the context in which it occurs. The processing of syntactic information, however, correlates with either a left anterior negativity (LAN) or late centro-parietal positivity generally referred to as the P600 component. In this connection very apt is the concise statement of Friederici et al. ${ }^{12}$ that the LAN is related to the processing of word category information in phrasal context or, in other words, that it reflects the first stage of syntactic parsing. The late centro-parietal positivities, in contrast, arise with the processing of a number of differ- ent syntactic anomalies including violations of obligatory syntactic structures and violations of syntactic preferences requiring syntactic reanalyses.

In this context is worth mentioning the results of Kuperberg et al. ${ }^{31}$. They investigated electrophysiological correlates of processing the conceptual relationship between a noun phrase (NP) that precedes a verb and the verb itself. They showed that two different types of conceptual noun-verb violation in a simple English sentence elicit different ERP waveforms. Pragmatic violations (the particular thematic role assigned by the verb to its preceding NP is inconsistent with overall context of the sentence) evoked robust and widespread N400 effect while animacy violations (the animate NP preceding the critical verb is replaced by an inanimate NP) elicited a centro-parietally distributed P600 effect. These results prove unambiguously that due to their sensitivity, ERPs reflect very small syntactic or semantic anomalies in English sentences.

Kuperberg's et al. ${ }^{31}$ results motivated us to undertake an experiment with native Czech speakers (L1) possessed of a perfect knowledge of English (L2). The off-line analysis of ERPs to critical verbs of correct and violated English or Czech sentences as well as accuracy rate for English and Czech sentences processing was expected to answer following questions:

(1) Can Kuperberg's et al. results be generalized across different native languages, such as Czech?

(2) Does language itself (either a native language or a later learnt foreign language) affect in the same way or not ERPs components amplitudes when brain is processing the same language phenomena?

It should be stressed here that intended experiment could be carried out due to the generosity of Mrs. Gina 
Kuperberg, who gave us permission to use in our experiment the "Linguistic stimuli" ${ }^{32}$ (four different types of English sentences) that she and her colleagues designed and applied in their neurolinguistics experiments.

The present paper summarizes the main results of our experiment.

\section{METHODS}

\section{Subjects}

The subjects in an experiment were 13 twenty-threeyear full-time students of English Philology taught by the staff of Department of English and American Studies of the Philosophical Faculty of Palacký University in Olomouc. However, data from two subjects were excluded due to errors in data acquisition. They all began learning English at school in the Czech Republic around the age of 15 and their present knowledge of English (L2) can be rated as excellent ( $\mathrm{C} 2$ level according to The Common European Framework ${ }^{53}$ in its political and educational context). All participants were right-handed females. We purposely did not include the other sex in the experimental group to eliminate the possible gender effect on ERPs and the decision time (DT) - see Petrek ${ }^{40}$, 33 . All participants' vision was normal or corrected to normal. The native language (L1) of each was Czech. All subjects gave their informed consent to the procedure.

\section{Stimuli}

Words forming English or Czech sentences, the plausibility of which was judged by a subject, served as stimuli to evoke ERPs. A total of 360 sentences represented by the four different types (see foot-notes) were used in our experiment. The first type ${ }^{(1 a)}$ (marked by us V0) represents coherent sentences and the filler sentences ${ }^{(1 b)}$, i.e. sentences without linguistic violation, the second type ${ }^{(2)}$ (V1) sentences with thematic role animacy violation, the third type ${ }^{(3)}(\mathrm{V} 2)$ sentences with non-thematic role pragmatic violation. Kuperberg et al. ${ }^{31}$ used this sentence classification in their paper that presented results of an analysis of ERPs parameters with processing conceptual relationships between nouns and verbs by native speakers in simple English sentences.

Here, in short, are the main features of the four types the sentences. In as much as all English sentences were borrowed from the paper of Kuperberg et al. ${ }^{31}$ and Czech sentences were constructed on the same principle by us it will be reasonable to take Kuperberg's sentence characteristics.

In the summary of the cited paper we read the following. "In all cases, the critical verb assigned a thematic role of 'agent' to its subjects NP. In non-violated sentences (e.g. 'For breakfast the boys would only eat ...'), the preceding NP was animate ('boys') and was a likely agent for a given

\footnotetext{
(1a) For breakfast the boys would only eat toast and jam.

(1b) This exciting novel could keep me occupied for many hours.

(2) For breakfast the eggs would only eat toast and jam.

(3) For breakfast the boys would only bury toast and jam.
}

verb ('eat') given its preceding context ('For breakfast') . In both types of conceptually violated sentences, the NPs were unlikely agents for the verbs given their preceding contexts. In 'thematic role animacy violations' (e.g. 'For breakfast the eggs would only eat ...'), the NP was inanimate ('eggs') and was therefore more likely to occupy the role of 'theme' than 'agent', i.e. eggs, being inanimate, cannot eat but only be eaten. In the 'non-thematic role pragmatic violations' (e.g. 'For breakfast the boys would only bury ...'), the thematic role of agent assigned by the verb ('bury') to its preceding NP ('boys') is inherently acceptable (boys can bury), but the sentence is still pragmatically incongruous given the preceding context ('At breakfast')." Thus, the differences between both sentences lie (see p. 118) "in the precise relationship between the verbs, their preceding NPs, and preceding context". In another place (p. 121) are specified the filler sentences - "all had inanimate NPs but that used verbs that do not render the sentences violated" (see the foot-note number 1b).

A total of 360 sentences (180 English sentences were randomly chosen from Kuperberg's list of "Linguistic stimuli" ${ }^{32}$ and 180 Czech sentences were created by us) were used in our experiment. The sentences were classified into nine blocks of 40 sentences each. Three blocks included only English sentences, another three only Czech ones, and the last three blocks half English and half Czech sentences. Equal numbers of V0, V1, V2 and filler sentences were comprised of nine blocks each. The sentences in each block were distributed randomly and none of them repeated more than once. A balanced $3 \times 3$ Latin square design was used to arrange 9 blocks in an experimental sequence.

\section{Presentation of stimuli}

The SciWorks Version 4, the Experimenter's WorkBench 32 Data Acquisition and Experiment Control Software (DataWave Technologies, Longmont, CO) was used to control stimulus presentation, regulate the timing of events, and record the responses of participants. During the experiment, participants were seated in a comfortable chair approximately $120 \mathrm{~cm}$ in front of a computer screen (SONY, Model: SDM-X72). Subjects were tested individually in a darkened, sound-attenuated, and electrically shielded room. Sentences were presented word-by-word on a computer monitor. The timing of word stimuli was checked by a photodiode. Stimuli appeared in white with grey background. When displayed, the stimuli subtended $0.43^{\circ}$ of vertical visual angle and $2.6^{\circ}-2.9^{\circ}$ of horizontal visual angle. A second monitor, located outside the testing room, allowed the experimenter to view the stimulus shown on each trial.

The whole experiment lasted approximately one hour and ten minutes. Pauses of 1.5-2.0 minutes separated individual blocks. Before the experiment began, a practice set of 20 sentences was presented. After the end of the experiment, all participants were administered the Freiburg Personality Inventory (FPI) in the modified version for Czech and Slovak populations ${ }^{29}$.

Each trial (one sentence) began with central presentation of a white asterisk for one second. Then a word 
appeared on the screen for $250 \mathrm{~ms}$ with an inter-stimulus interval of $750 \mathrm{~ms}$ separating words. The last word of each sentence was marked with a period. Thereafter a question mark arose on the screen and remained there for $2000 \mathrm{~ms}$. The participant had to decide by that time which type of sentence was presented. This was resolved by pressing one of the three buttons of the three-button Logitech mouse OEM, M-M35. Pursuant to instruction before the session, a participant with her right index finger pressed the left mouse-button when a V0 sentence or a filler sentence was presented, the middle button when it was a V1, and the right button when it was a V2 sentence. Mouse-button pressing activated concurrently the special software ESO evaluating the decision time for the given sentence.

\section{Data acquisition}

EEG was recorded from 8 scalp sites by tin electrodes attached to an elastic cap (Electro-Cap International, Eaton, $\mathrm{OH}$ ). Electrodes were placed at scalp positions F3, $\mathrm{F} 4, \mathrm{C} 3, \mathrm{C} 4, \mathrm{P} 3, \mathrm{P} 4, \mathrm{~T} 3$, and T4 of the International 10-20 system; for technical reasons records $\mathrm{T} 3$ and $\mathrm{T} 4 \mathrm{did}$ not undergo off-line evaluation. One electrode was also placed at the outer canthus of the right eye to monitor eye movements. Scalp electrodes were referred to linked earlobes; the ground electrode was placed at Fpz. Electrodes impedance was kept below $3 \mathrm{k} \Omega$ throughout the experiment.

Following electrodes application, subjects were instructed to read each word silently and attentively. They were also asked to focus on the asterisk whenever it appears on the screen and to avoid blinks or other movements during the presentation of stimuli.

The EEG signal was amplified by cascade of two amplifiers (amplifiers EKe, OTE Biomedica, Firenze, and Amplifier Neuralynx, Tucson, Arizona) with bandpass of $0.01-100 \mathrm{~Hz}$ and continuously sampled at $1 \mathrm{kHz}$ per channel by an A/D converter; the resolution of the system is $0.122 \mu \mathrm{V} / \mathrm{bit}$. The digitised records were saved to the hard disk of a computer for later off-line replay and analysis.

\section{Data analysis}

The SciWorks Version 4, the DataWave CP Analysis Modules and Data Editing Software were used for off-line analysis of experimental data. The proper analysis ran as follows: Digital filtering of records (bandpass 1-30 Hz), cutting filtered records for averaging - the start points of the cut segment of EEG records were time-locked to photodiode signal, and detection of ERPs by averaging.

Utilizing the software listed above we were able to extract from an average ERP many specific numerical single values in cursor-defined regions (time windows). For our purpose ten variables were chosen. The first three variables (B 40-250, B 250-400 and B 400-600) assessed the $\operatorname{area}^{(4)}$ between the wave form and the zero line connecting the cursors. Another two variables (A 40-250 and A 400-600) evaluated the area between the waveform and the baseline which was calculated by software using the

(4) The unit of the area (numerical integral value) is $\mathrm{X}$-axis units times Y-axis units and is calculated using Simpson's rule. first five points of the waveform. An additional four variables (P 100-250, P 400-600, N 100-250 and N 250-440) assessed the maximal positive $(\mathrm{P})$ and negative $(\mathrm{N})$ voltages from baseline in a defined time window. The last measured value characterized a latency of negativity peaking at intervals from 250 to 440 milliseconds (so-called N400 ERPs component).

StatSoft software package (StatSoft, Tulsa, OK) was used for statistic processing of behavioral and ERPs data of participants. In this connection, however, it should be added that, as revealed in an off-line analysis, we did not fully succeed in acquiring more information about ERPs dynamics during language processing through the evaluation of more ERPs parameters. Some of the chosen ERPs parameters show high mutual correlation $(p<.001)$ and that is beyond dispute the main reason why our expectation was not met. This conclusion does not worry us, in fact it shows that equivalent information can be acquired with a smaller effort, i.e. by evaluation of a smaller data bulk.

\section{RESULTS}

\section{ERPs during English and Czech sentences processing}

Our recent papers ${ }^{40,44}$ have shown that in the ideal case in the first $800 \mathrm{~ms}$ after the onset of the word stimulus originate ERPs formed by the three distinct positive and four negative waves. Mean latency of their positive P1 wave oscillates around $132 \mathrm{~ms}, \mathrm{P} 2$ around $229 \mathrm{~ms}, \mathrm{P} 3$ around $483 \mathrm{~ms}, \mathrm{~N} 1$ around $179 \mathrm{~ms}, \mathrm{~N} 2$ around $285 \mathrm{~ms}$, $\mathrm{N} 3$ around $398 \mathrm{~ms}$ and N4 around $728 \mathrm{~ms}$.

The shape and latencies of individual ERPs waves (see Figure 1) elicited by critical verbs of both English and Czech sentences in the present experiment do not differ in principle from those listed above. Nevertheless, ERPs to critical verbs of English and Czech sentences show differences in their amplitudes of N400. This fact is graphically illustrated in the next parts of the text.

The results of the multivariate analysis of variance (see Table 1) prove unambiguously that all amplitude characteristics of analysed ERPs are affected by the language of presented sentences. Neither the site of recording electrodes on the scalp nor the participant herself influences them. Hereafter we will not analyse the last two items. It turned out namely that an evaluation of both main effects (Electrode and Participant) and their interactions with other independent variables in principle bring nothing new in solving the problem. Main effects are significant because some subjects persistently show higher or low mean values of tested ERPs parameters during the experiment, or because in both hemispheres the amplitude of each ERPs component is smaller in frontal electrodes and larger in central and parietal electrodes.

Considering the above, we direct our attention only to an analysis of ERPs parameters which could predicate processing the conceptual relationships that occur between nouns and verbs both in simple English and Czech sentences. The measured parameters, i.e. the mean values of a numerical integral of ERPs waves and the mean val- 
ues of their maximal positive and negative amplitudes in a given time window, are summarized in Table 2. From this follows:

First, mean values of the numerical integral are significantly higher during the presentation of Czech sentences than during the presentation of English ones in all the time windows except the window B 40-250. Maximal

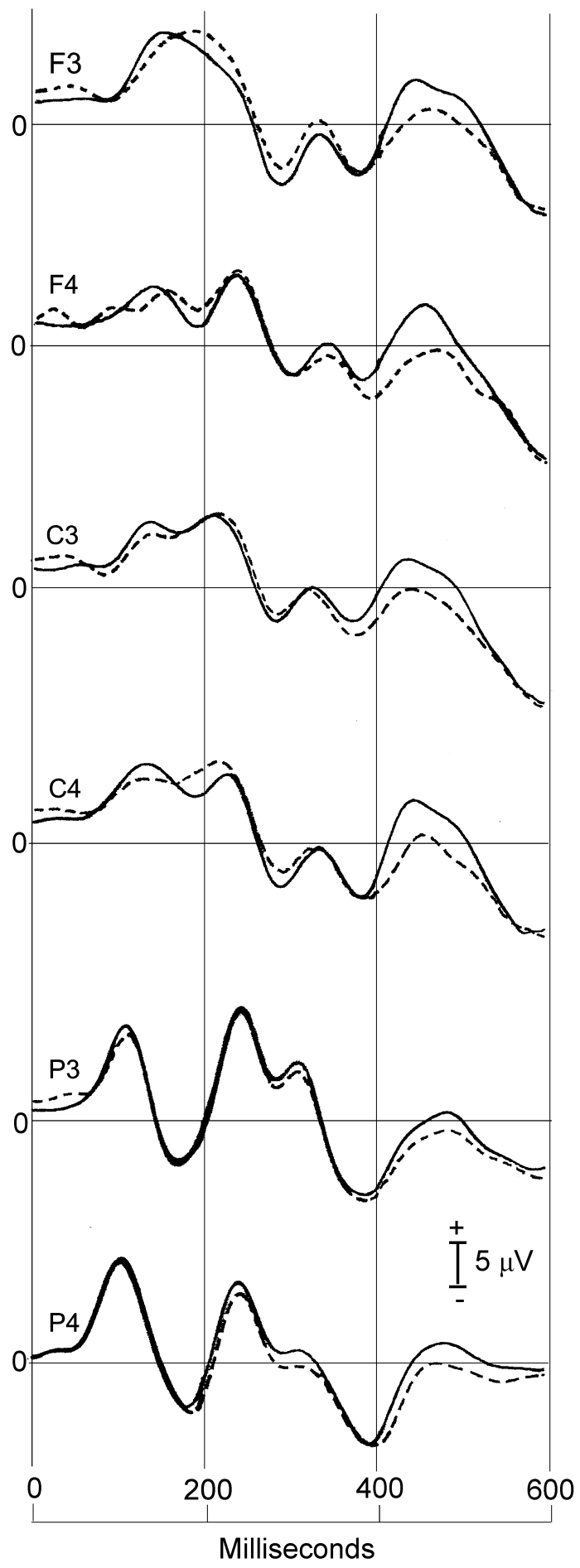

Fig. 1. Grand average ERPs for the experimental group $(n=11)$ for critical verbs of Czech (full line) and English (dashed line) simple sentences. (F3/F4) $=$ frontal, $(\mathrm{C} 3 / \mathrm{C} 4)=$ central, and $(\mathrm{P} 3 / \mathrm{P} 4)=$ parietal electrode locations. positive ERPs amplitudes in both the $\mathrm{P} 100-250$ and the P 400-600 time windows behave similarly. The only exception is the maximal negative ERP amplitude in the $\mathrm{N}$ 250-440 time window - the difference between means is not significant.

Second, electrophysiological correlates reflect the type of violations of conceptual relationships (V0, V1 and V2) that occurs between nouns and verbs in Czech or in English sentences. The differences between means are significant in most cases (for details see the Table 2).

Third, there are significant interactions between the sentence type (V0, V1 and V2) and a language (En or $\mathrm{Cz}$ ); Fig. 2 demonstrates this fact more graphically. The main results regarding mutual interactions may be summarized as follows:

(a) The English language (En) affects the V1 mean values of numerical integral and the maximal positive ERPs amplitude in principle similarly in all time windows - the mean values for V1 are significantly higher than mean values for $\mathrm{V} 0$.

(b) So unambiguous results do not show, however, the interaction between the Czech language and V0 orV1 sentence types. The differences between means for V0 and V1 are often insignificant (for details see Table 2 and Figure 2). Besides, there is an opposite relation between the means in the B 400-600 time window - the mean value of the numerical integral for V1 is significantly smaller than that for V0. The same is true for the maximal positive ERPs amplitude measured in the time window P 400600.

(c) No less interesting is a mutual interaction between a language (En or $\mathrm{Cz}$ ) and V1 and V2 mean values of the numerical integral or maximal ERPs amplitudes.

In the English language they are all differences between means for V1 and V2 significant in all the time windows except the time window B 40-250 and P 100250. They are smaller for V2 than for V1 (see Table 2 and Figure 2).

In the Czech language the differences between means for V1 and V2 are significant too. Nevertheless, there is one distinct difference: Contrary to English the measured parameters for Czech V2 sentences are higher than those for V1.

To make the picture complete we note that an average latency N400 ERPs components elicited by all Czech or English verbs differed from each other; for Czech verbs it was significantly shorter (334.8 ms) than for English ones $(345.9 \mathrm{~ms})$ - Kruskal-Wallis test: $\mathrm{H}(1, \mathrm{~N}=396)=$ $7.25972, \mathrm{p}=.0071$. However, insignificant were differences in a latency N400 ERPs component elicited only by verbs of English and Czech V0, V1 and V2 sentences.

\section{Errors - an index of accuracy rate of English and Czech sentences processing}

The main results are summarized in Figure 3. It is evident (see the first column) that more errors were made by our participants in processing English sentences (18.1\%) than in processing Czech ones $(11.7 \%)$. The difference between both values is significant $(p<.05)$. 
Table 1. Multivariate analysis of variance: ERPs parameters

\begin{tabular}{|l|c|c|c|c|c|c|}
\hline & \multicolumn{9}{|l|}{$\begin{array}{l}\text { Table of all effects: ERPs data } \\
\text { Sigma-restricted parametrization } \\
\text { Effective hypothesis decomposition }\end{array}$} \\
\cline { 2 - 9 } Effect & Test & Value & F & Effect $d f$ & Error $d f$ & $\mathrm{p}$ \\
\hline Intercept & Wilks & 0.003467 & 8685.951 & 9 & 272.000 & 0.000000 \\
Participant & Wilks & 0.000001 & 139.313 & 90 & 1855.052 & 0.000000 \\
Language & Wilks & 0.523256 & 27.536 & 9 & 272.000 & 0.000000 \\
Sentence & Wilks & 0.783466 & 3.922 & 18 & 544.000 & 0.000000 \\
Electrode & Wilks & 0.001578 & 87.557 & 45 & 1219.825 & 0.000000 \\
Participant $\times$ Language & Wilks & 0.148450 & 6.694 & 90 & 1855.052 & 0.000000 \\
Participant $\times$ Sentence & Wilks & 0.088631 & 4.291 & 180 & 2262.186 & 0.000000 \\
Language $\times$ Sentence & Wilks & 0.644626 & 7.420 & 18 & 544.000 & 0.000000 \\
Participant $\times$ Electrode & Wilks & 0.000004 & 16.679 & 450 & 2435.846 & 0.000000 \\
Language $\times$ Electrode & Wilks & 0.806140 & 1.338 & 45 & 1219.825 & 0.068926 \\
Sentence $\times$ Electrode & Wilks & 0.832231 & 0.565 & 90 & 1855.052 & 0.999647 \\
\hline
\end{tabular}
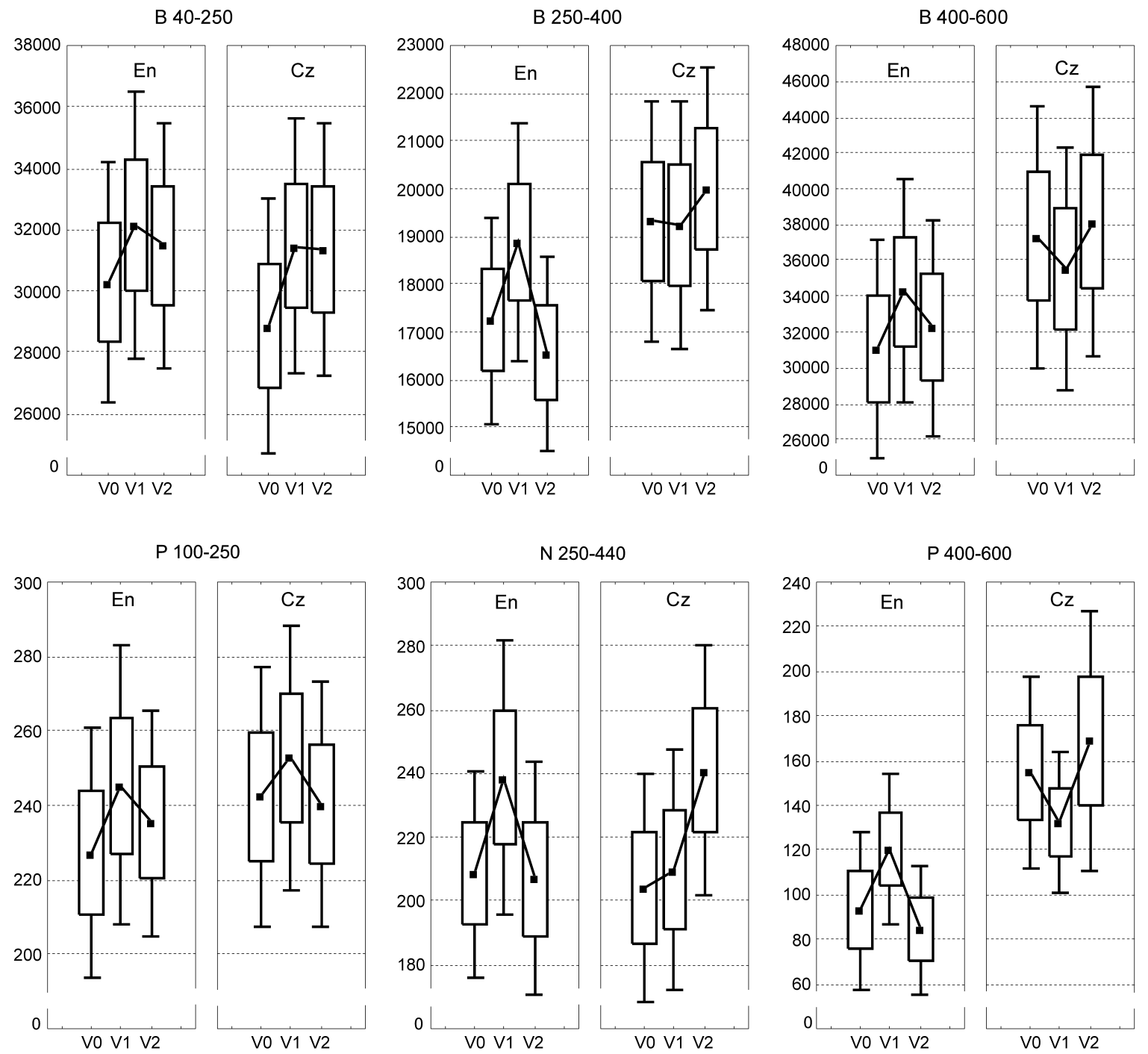

Fig. 2. The ERPs parameters: The mean values of numerical integrals (the upper half) and maximal positive (P) and negative $(\mathrm{N})$ amplitudes (the bottom half) in a defined time window during processing of English (En) and Czech $(\mathrm{Cz})$ sentence types V0, V1 and V2.

Midpoint - mean, Box around the midpoint - Std. Error, Whiskers - 1/25 of St. Deviation. For other details see the text to Table 2 . 
More detailed analysis showed (see columns 2 and 3) that the accuracy rate depends apart from a language also on the type of the sentence - Kruskal-Wallis test: H (2, $\mathrm{N}=66)=15.66592, \mathrm{p}=.0004$. The processing of English sentences V1 and V2 gave rise to more errors - V1 $23.8 \%$ and V2 $21.0 \%$. In Czech sentences most errors fell only on V2 sentences (18.7\%). The accuracy rate for Czech V1 sentences ( $7.8 \%$ of errors) did not differ in principle from that for Czech V0 sentences $(8.7 \%)$. A post-hoc comparison of mean ranks for all groups showed that all differences between means are significant except two pairs of means (V1 vs. V2 - the second column, and V0 vs. V1 - the third column in Figure 3).

Thus, there is an interaction between the language (En or $\mathrm{Cz}$ ) and the type of visually presented sentences (V0, V1 and V2), i.e. the language affects the accuracy rate of online processing of conceptual relationships between noun phrases and verbs in simple English and Czech sentences. The data in the second and the third column in Figure 3 reveal that false evaluations both English and Czech V0 and V2 sentences show practically the same accuracy rate (about $9 \%$ of errors for $\mathrm{V} 0$ and about $20 \%$ for V2). However, that is not the case with V1 sentences - in accuracy rate the Czech V1 sentences are better off (only $7.8 \%$ of errors) than the English ones (23.8\%).

In conclusion we note that each of our participants showed practically the same accuracy rate in an assessment either English or Czech V0, V1 and V2 sentences - Kruskal-Wallis test: $\mathrm{H}(10, \mathrm{n}=66)=10.63719$, $\mathrm{p}=.3865$.

\section{The lexical decision time during English and Czech sentences processing}

From Figure 4 (the first column) it follows that the language of presented sentences determines the decision time value (DT). The Czech sentences show significantly shorter DT than do the English ones $(p<.05)$. Furthermore the DT value depends on the type of presented sentence too - Kruskal-Wallis test: $\mathrm{H}(2, \mathrm{~N}=3960)=106.2931$, $\mathrm{p}=.000$. In other words: there are mutual interactions between language ( $\mathrm{En}$ and $\mathrm{Cz}$ ) and sentence types (V0, $\mathrm{V} 1$ and V2), which come through both in accuracy rate of sentence processing (see above), and DT length.

The average DTs of all English and Czech V2 sentences are practically the same (En - $1124.5 \mathrm{~ms}, \mathrm{Cz}$ - 1096.6 ms), but they are always longer than DTs for V0 (En - 975.0 ms, Cz - 1000.4 ms) and V1 (En -960.0 ms, $\mathrm{Cz}-825.0 \mathrm{~ms}$ ) sentences. Moreover, DTs of English V0 and V1 sentences do not differ from each other whereas DTs of Czech V0 and V1 sentences are different - DTs of Czech V1 sentences are significantly shorter (compare the second and third columns in Figure 4).

Finally a more detailed analysis of an individual subject's DT showed (see Figure 5) great within-group variability; the DT ranged from 700 to $1300 \mathrm{~ms}$ during English and Czech sentences processing. Further, the Kruskal-Wallis test $[\mathrm{H}(10, \mathrm{~N}=3960)=627.125, \mathrm{p}=.000]$ showed that differences in the average DT some of our participants are significant.
A post-hoc comparison of mean ranks for all groups allowed us in accordance with subject's average DT to separate three discrete groups of subjects. The first group represented only two subjects (the average DT of $702.7 \mathrm{~ms}$ ), the second one six subjects with average DT of $964.5 \mathrm{~ms}$ and the three spare subjects belonged to the third one (the average DT $1260.6 \mathrm{~ms}$ ).

It was also shown that there is a mutual relationship between the average DT value of each of the three groups and their average score on some FPI parameters (see Table 3 ). This applies especially to parameters FPI 3, FPI 4, FPI N, FPI 6, FPI 7 and FPI M - the first three correlate positively with the appropriate average DT value, the last three show negative correlation.

\section{DISCUSSION}

The results of our experiment have shown that on-line processing of the same types of simple Czech or English sentences by adult Czech-English bilinguals attended ERPs differing in their main characteristics. Therefore, it was especially the language of the presented sentence which in our experiment determined the parameters of participant's ERPs. The early ERPs positivity/negativity as well as characteristics of their N400 and P600 waves often behaved differently during subject's assessment of Czech or English V0, V1 and V2 sentence types.

The site of recording electrode, it seems, played a secondary role in determination of tested ERPs parameters. It must be emphasized here that ERPs parameters elicited by critical verbs of Czech or English sentences showed the same dynamics. The numerical integral and amplitudes N400 or P600 showed slightly higher values in parietal sites than in frontal ones -naturally this holds only in a case when differences were real. Furthermore, both hemispheres behaved entirely identically in this situation.

Considering we borrowed English sentences from Kuperberg et al. ${ }^{31,32}$ and designed Czech sentences on the same principle, it will be more reasonable to compare our results with those of Kuperberg and her colleagues.

First of all we would like to stress that our results correspond with those of Kuperberg et al. in the electrophysiological correlates of first-language (L1) processing. The characteristics of ERPs of our subjects (Czech native speakers) during the processing of each of the three types of Czech sentences in principle were not different from those following the processing of the same types of English sentences by native English speakers taking part in Kuperberg's experiment.

Kuperberg et al. demonstrated that the N400 amplitude elicited by verbs of non-thematic role pragmatic violation sentences (V2 sentences) was significantly more negative-going than that elicited by the non-violated verbs (V0). However, they did not show significant differences in the N400 ERPs amplitudes to verbs of the thematic role animacy violated (V1) and non-violated (V0) sentences recorded in lateral sites of the scalp (F3/F4, C3/C4, $\mathrm{T} 3 / \mathrm{T} 4$ and $\mathrm{P} 3 / \mathrm{P} 4)$. We would like to recall here that the 
Table 2. Evaluated ERPs parameters: Mean values of the numerical integrals

(A - between the waveform and base line, B - between the waveform and zero line), maximal positive (P) and negative (N) amplitudes from baseline in a defined time window (40-250 ms, 250-400 ms and 400-600 ms), and the mean latency N400 component peaking in time window $250-420 \mathrm{~ms}$

\begin{tabular}{|c|c|c|c|c|c|c|c|c|c|c|c|c|}
\hline Language & Sentence & $\mathrm{N}$ & В $40-250$ & B $250-400$ & B 400-600 & A $40-250$ & A $400-600$ & P $100-250$ & P 400-600 & N 100-250 & N 250-440 & L N400 \\
\hline \multirow[t]{2}{*}{$\begin{array}{l}\text { English } \\
\text { Czech }\end{array}$} & & $\begin{array}{l}198 \\
198\end{array}$ & $\left.\begin{array}{l}31299 \\
30560\end{array}\right]$ & $\left.\begin{array}{l}17559 \\
19520\end{array}\right]$ & $\left.\begin{array}{l}32522 \\
36985\end{array}\right]$ & $\left.\begin{array}{l}18884 \\
20134\end{array}\right]$ & $\left.\begin{array}{c}8205 \\
13139\end{array}\right]$ & $\left.\begin{array}{l}236 \\
245\end{array}\right]$ & $\left.\begin{array}{c}99 \\
152\end{array}\right]$ & $\begin{array}{l}136 \\
141\end{array}$ & $\begin{array}{l}206 \\
218\end{array}$ & $\left.\begin{array}{l}346 \\
335\end{array}\right]$ \\
\hline & $\begin{array}{l}\text { V0 } \\
\text { V1 } \\
\text { V2 }\end{array}$ & $\begin{array}{l}132 \\
132 \\
132\end{array}$ & ) & $\begin{array}{l}18278 \\
{\left[\begin{array}{l}19062 \\
18278\end{array}\right]}\end{array}$ & $\left.\left.\begin{array}{l}34179 \\
34888 \\
35193\end{array}\right]\right)$ & $\left.\begin{array}{l}18447 \\
20863 \\
19216\end{array}\right]$ & $\begin{array}{l}10471 \\
10812 \\
10734\end{array}$ & $\begin{array}{l}235 \\
{\left[\begin{array}{l}249 \\
238\end{array}\right]}\end{array}$ & $\begin{array}{l}124 \\
127 \\
127\end{array}$ & $\left.\begin{array}{l}133 \\
148 \\
140\end{array}\right]$ & $\left.\left.\begin{array}{l}206 \\
224 \\
224\end{array}\right]\right)$ & $\begin{array}{l}335 \\
342 \\
343\end{array}$ \\
\hline $\begin{array}{l}\text { English } \\
\text { English } \\
\text { English }\end{array}$ & $\begin{array}{l}\text { V0 } \\
\text { V1 } \\
\text { V2 }\end{array}$ & $\begin{array}{l}66 \\
66 \\
66\end{array}$ & $\left.\left.\begin{array}{l}30283 \\
32129 \\
31486\end{array}\right]\right)$ & {$\left[\begin{array}{l}17236 \\
18884 \\
16555\end{array}\right]$} & $\left.\left[\begin{array}{l}31058 \\
34270 \\
32237\end{array}\right]\right)$ & $\left.\begin{array}{l}17747 \\
19978 \\
18926\end{array}\right]$ & {$\left[\begin{array}{l}8024 \\
{\left[\begin{array}{l}9417 \\
7175\end{array}\right]}\end{array}\right.$} & $\left.\begin{array}{l}227 \\
245 \\
235\end{array}\right]$ & $\begin{array}{c}93 \\
{\left[\begin{array}{c}121 \\
84\end{array}\right]}\end{array}$ & $\left.\left.\begin{array}{l}124 \\
142 \\
143\end{array}\right]\right)$ & {$\left[\begin{array}{l}209 \\
239 \\
207\end{array}\right]$} & $\begin{array}{l}341 \\
350 \\
346\end{array}$ \\
\hline $\begin{array}{l}\text { Czech } \\
\text { Czech } \\
\text { Czech }\end{array}$ & $\begin{array}{l}\text { V0 } \\
\text { V1 } \\
\text { V2 }\end{array}$ & $\begin{array}{l}66 \\
66 \\
66\end{array}$ & $\left.\begin{array}{l}28853 \\
31470 \\
31356\end{array}\right]$ & {$\left[\begin{array}{l}19320 \\
19240 \\
20001\end{array}\right]$} & $\begin{array}{l}37300 \\
{\left[\begin{array}{l}35506 \\
38150\end{array}\right]}\end{array}$ & {$\left[\begin{array}{l}19147 \\
21748 \\
19506\end{array}\right]$} & $\left.\begin{array}{r}12918 \\
12208 \\
14293\end{array}\right]$ & $\begin{array}{l}242 \\
253 \\
240\end{array}$ & $\left.\left[\begin{array}{l}155 \\
133 \\
169\end{array}\right]\right)$ & $\begin{array}{l}141 \\
133 \\
131\end{array}$ & {$\left[\begin{array}{l}204 \\
210 \\
241\end{array}\right]$} & $\begin{array}{l}331 \\
335 \\
340\end{array}$ \\
\hline
\end{tabular}

The unit of the area (numerical integral) is X-axis units $(\mathrm{mV})$ times $\mathrm{Y}$ - axis units (ms) and is calculated using Simpson's rule. P and $\mathrm{N}$ voltages in $\mathrm{mV}$, latency $\mathrm{N} 400$ in ms. Amplitude calibration: $1 \mu \mathrm{V}=40 \mathrm{mV}$. Parenthesis - the difference between means is significant $(\mathrm{p}<.05)$.

Table 3. The average decision time (DT) for English (En) and Czech (Cz) sentences and average FPI score (Freiburg Personality Inventory) - both for each of the three groups of subjects participating in the experiment

\begin{tabular}{|l|c|c|c|c|c|c|c|c|c|c|c|c|c|c|c|c|}
\hline Group & N & En+Cz & DT_En & DT_Cz & FPI 1 & FPI 2 & FPI 3 & FPI 4 & FPI 5 & FPI 6 & FPI 7 & FPI 8 & FPI 9 & FPI E & FPI N & FPI M \\
\hline DT_S & 2 & 702.7 & 743.7 & 661.7 & 78.3 & 79.2 & 50.4 & 25.6 & 55.8 & 76.4 & 71.0 & 65.3 & 78.6 & 51.0 & 38.1 & 66.7 \\
DT_M & 6 & 964.5 & 975.1 & 954.1 & 67.9 & 70.1 & 58.7 & 49.6 & 84.4 & 52.4 & 64.8 & 48.7 & 86.9 & 70.6 & 53.6 & 60.1 \\
DT_L & 3 & 1260.6 & 1259.1 & 1256.3 & 69.9 & 78.9 & 77.3 & 56.8 & 62.4 & 34.7 & 55.4 & 87.4 & 69.4 & 56.4 & 63.1 & 51.7 \\
\hline
\end{tabular}

FPI 1 - nervousness, FPI 2 - spontaneous aggression, FPI 3 - uncertainty, FPI 4 - irritability, FPI 5 - sociability, FPI 6 - mildness, self-confidence, FPI 7 - reactive aggression, endeavour to be dominant, FPI 8 - moderation, FPI 9 - directness, straightness, FPI extraversion, FPI N - emotional lability, FPI M - masculinity.

same results brought an analysis of behaviour of the $\mathrm{N} 400$ component evoked in our subjects by verbs of Czech V0, $\mathrm{V} 1$ and V2 sentences.

However, substantially less congruity is shown by the P600 wave in both compared experiments. The main differences are in V1 sentence type. We have shown that the P600 elicited by verbs of V1 Czech sentences was significantly smaller than the P600 to verbs of V0 and V2 Czech sentences. In contrast to us, Kuperberg et al. showed that P600 elicited by thematic role animacy violation (V1) was significantly more positive-going than that elicited by nonthematic role pragmatically violated verbs (V2).

These discrepancies do not appear so great if we consider the literature that clarifies the origin and functional significance of the P600. Many authors assert that P600 reflects some aspects of syntactic analysis ${ }^{12,17,20,23,38}$ whereas others produce evidence that $\mathrm{P} 600$ is not syntaxspecific $^{6,23}$. Thus the published data are ambiguous.

Nevertheless, it should be recognized that the different behaviour of P600 in our experiment reflects some particularities of Czech and English languages that could project also the language processing of Czech and English sentences. Behavioural correlates (the accuracy rate and DT) for V1 sentences processing support this assumption. According to Kuperberg et al. ${ }^{31}$ English V1 sentences, i.e. sentences with thematic role animacy violation, showed significantly greater accuracy rate than either the control sentences (V0) or the non-thematic role pragmatically violated sentences (V2). On the other hand, our findings displayed virtually the same accuracy rate for Czech V1 and $\mathrm{V} 0$ sentences and significantly lower accuracy rate (more errors) for V2 sentences. Moreover, they showed that Czech V1 sentences are processed with higher speed than the others and arguably with the subject's smaller effort - the DT for V1 Czech sentences was the shortest among the sentence types.

Regardless of the fact whether these considerations explain real causes of discussed discrepancies or not, our results entitle us with some caution to conclude: Czech native speakers process the specific syntactic/semantic violation in a similar manner to subjects whose first-language is English. In short, the brain of native speakers probably follows identical rules in processing the same language phenomena.

Let us now give our attention to the behaviour of ERPs components attending English V0, V1 and V2 sentences processing by our participants, i.e. by Czech native speakers, who learned English after the age of 15 . Here some ERPs features showed different parameters during the processing of English than of Czech sentences.

All our participants displayed the N400 component, which is usually attributed to semantic integration proc- 

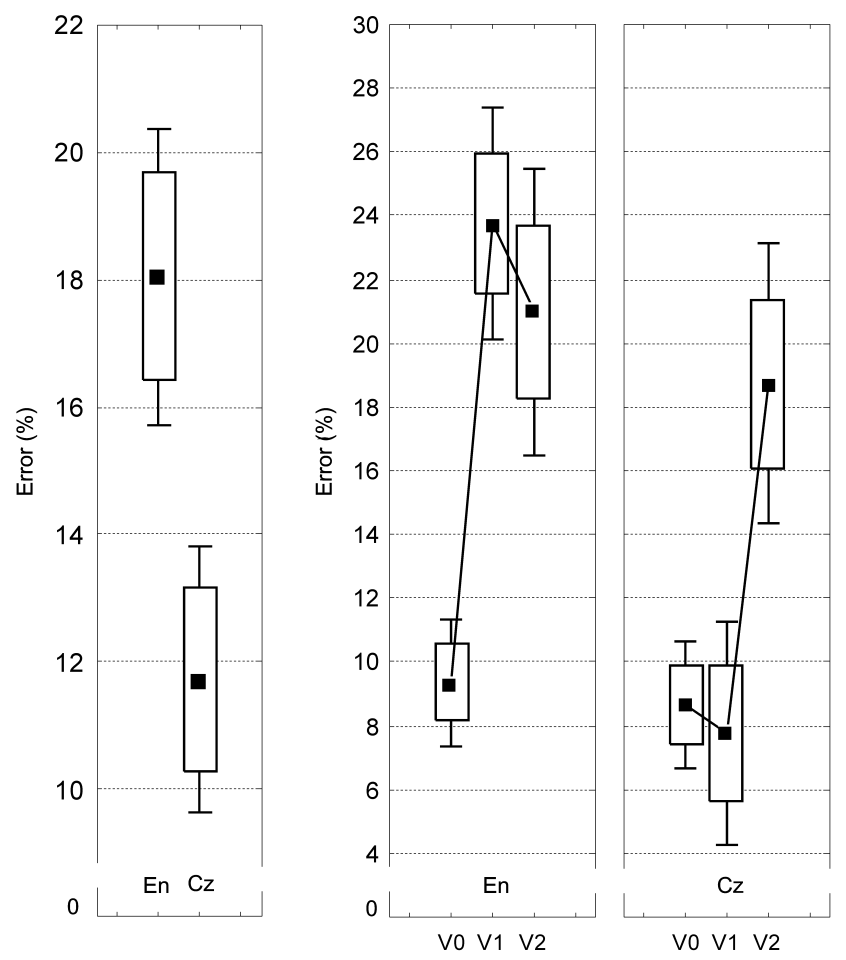

Fig. 3. The average number of errors (accuracy rate) of processing English (En) and Czech $(\mathrm{Cz})$ sentences. For other details see the text to Figure 2.

esses. However, its average latency to English verbs was significantly longer than that to Czech verbs. The longer latency of the N400 component in bilingual's second language than in their first language was described also by others $^{1,22,36,54}$.

The facts just mentioned denote more difficult semantic processing of foreign language sentences by non-native speakers. Therefore, it is understandable why our participants showed the longer N400 average latency during processing of English sentences than during processing of Czech one. Moreover, the longer DT shown by our participants during the processing of English sentences gives evidence of the considerable effort that goes into such language operations.

Besides differences in average latencies $\mathrm{N} 400$ components there appeared a few other differences. One of the most prominent is the finding demonstrating the same dynamics of all ERPs parameters during the processing of English sentences by Czech native speakers - the numerical values of each tested ERPs parameter were higher at processing English V1 sentences than during processing the other two sentences (V0 and V2); the Czech sentences did not show such uniformity - see above. Why this is, we do not know. Perhaps some further experiments might explain this observation.

The behavioural characteristics proved to be different too. Czech native speakers reached the same accuracy rate both for EnglishV1 and V2 sentences, but they achieved it with different DTs - the DT for V1 sentences was shorter
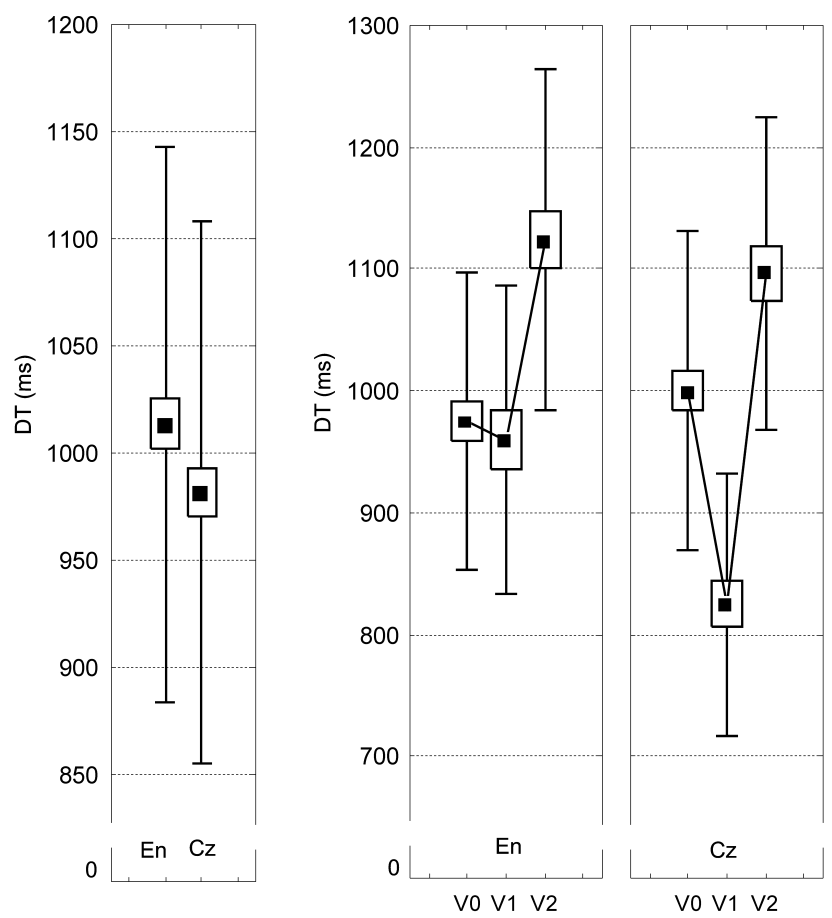

Fig. 4. The average decision time (DT) for processing of English (En) and Czech $(\mathrm{Cz})$ sentences. For other details see the text to Figure 2.

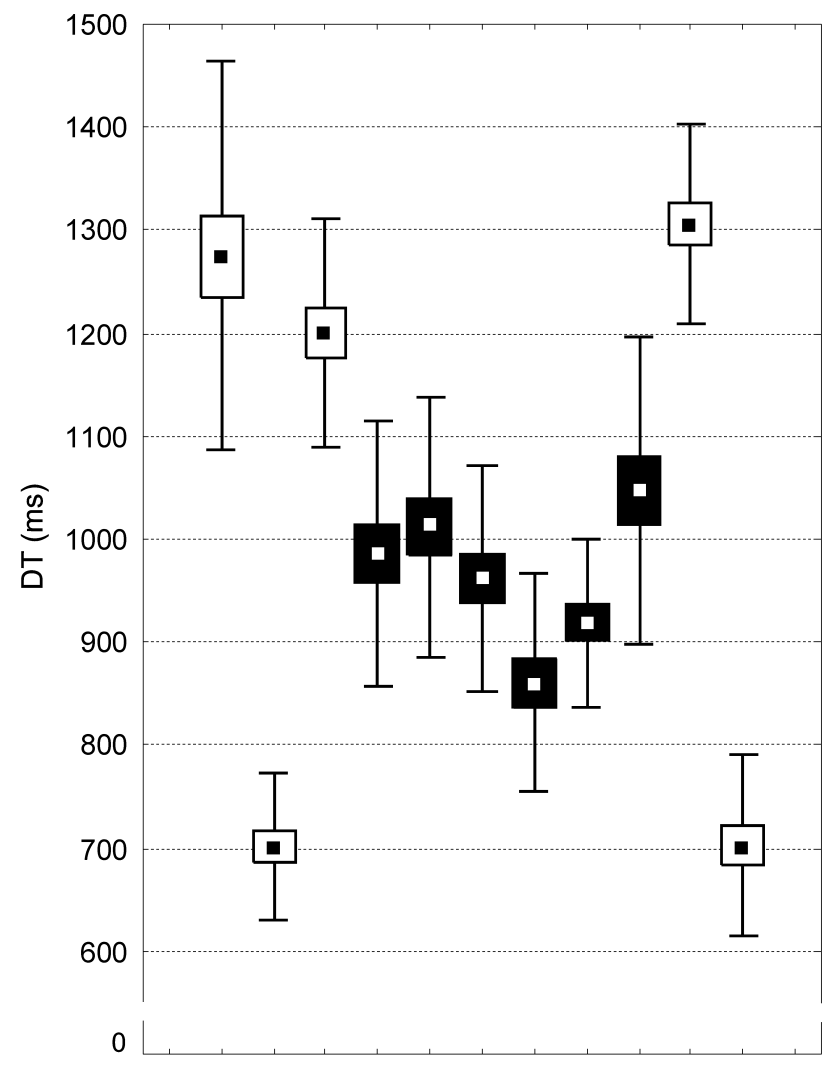

BR BA BU CE HO HU JE KR PR SL ST

Fig. 5. The average decision time (DT) of individual subjects (BR, BA, ..., ST) participating in the experiment 
than that for V2 and was almost identical with the DT for V0 sentences. On the other hand, DTs related to the processing of Czech V0, V1 and V2 sentences differed significantly from each other, but the DT for V1 sentences was the shortest of all.

Considering what was said, especially the accuracy rate for English V1 and V2 sentences, it seems likely that Czech native speakers were unable to discriminate the precise relationships between the verbs, their preceding noun phrases, and their preceding contexts. This finding will not seem so surprising if we consider the literature data demonstrating a relationship between the age of acquisition or exposure to a second language $e^{4,27,54}$. Thus, there are data showing that the age of acquisition represents the crucial variable for the degree of proficiency attained in a second language. In short, the earlier a second language is acquired, the higher the level of proficiency eventually attained by the user, especially with regards to both the syntactic and the lexico-semantic aspects of language.

All our participants have been studying English (L2) since the age of 15 - thus they count as adult (late) second learners of English, and this fact could account for their inability to notice during the language processing the fine nuances of conceptual relationships that occur between nouns and verbs in simple English V1 and V2 sentences, i.e. in sentences that are characterized by either thematic role animacy violation or non-thematic role pragmatic violation.

In conclusion we would like to add a few notes related to the utilization of the DT in language processing studies. In the best sense of the term, the DT reflects a general level of excitability of the central nervous system at the moment of solving a problem, which undoubtedly correlates with the subject's effort to solve the problem. On this account the DT can be utilized as a useful behavioural index of processes participating in solving manifold problems inclusive of those, which are connected with brain processing of various language phenomena.

However, it would be really so if all interested researchers took into consideration research data showing a mutual relationship between the DT and subject's personality traits and/or between personality traits and some characteristics of ERPs to language stimuli. The papers of some authors $\mathrm{s}^{5,8,46,52}$ belong to those which are confirming these relations. Our recent paper ${ }^{43}$ as well as the results presented in this paper acknowledges also the link between the DT and subject's personality traits.

What improvement in interpretation of experimental data the consideration of the subject's personality traits brings is shown graphically after a superficial examination of DT values presented in Figure 5. From this follows that the DT shows great within-group variability - its average values range from $700 \mathrm{~ms}$ to $1300 \mathrm{~ms}$. However, matching subject's personality traits with their DT revealed the existence of a relation between both variables. Subject's DT was the shorter, the lower was the score of depression or uncertainty (FPI 3) in the Freiburg's Personality Inventory (FPI) or the score of irritability (FPI 4) or the score of emotional instability (FPI N), and conversably. On the other hand, the DT negatively correlated with the score of placidity or self-confidence (FPI 6), with the score of reactive aggression or endeavour to be dominant (FPI 7), and also with the score of masculinity (FPI M), i.e. the longer the DT was, the smaller was the FPI value.

Additionally it should be stressed that the relatively small number of our participants does not allow us to make more detailed conclusions considering the contribution of these findings to processing of conceptual relationships within simple, unambiguous sentences. However, from the methodological viewpoint, the personality traits should not be ignored in experiments dealing with problems of brain language processing.

\section{CONCLUSION}

Czech native speakers process a specific syntactic/semantic violation in a similar manner as subjects whose first language is English. In short, the brain of native speakers probably follows identical rules in processing the same language phenomena.

There are numerous literature data showing that the age of acquisition represents the crucial variable for the degree of proficiency attained in a second language. In brief, the earlier a second language is acquired, the higher the level of proficiency eventually attained by the user is, especially in syntactic and lexico-semantic aspects of the language.

All our participants have been studying English (L2) since the age of 15 - thus they count as adult (late) second learners of English, and this fact could account for their inability to notice during the language processing the fine nuances of conceptual relationships that occur between nouns and verbs in simple English sentences, i.e. in sentences that are characterized by either thematic role animacy violation or non-thematic role pragmatic violation.

The DT shows great within-group variability. However, matching subject's personality traits with their DT revealed the existence of a relation between both variables. Therefore, the personality traits should not be ignored by researches using the DT in experiments dealing with problems of brain language processing.

\section{ACKNOWLEDGEMENTS}

The author wishes to thank Mrs S. Reznícková for her invaluable help conducting the experiment and analysing the data, as well as Mgr. J. Zapletalová for her advice in statistical data analysis. The all-round help of Prof. PhDr. J. Macháček,.CSc., is very much appreciated too.

\section{REFERENCES}

1. Ardal S, Donald MW, Meuter R, Muldrew S, Luce M. (1990) Brain responses to semantic incongruity in bilinguals. Brain Lang 39, 187-205. 
2. Balconi M, Pozzoli U. (2004) N400 and P600 or the role of the ERP correlates in sentence comprehension: Some applications to the Italian language. J Gen Psychol 131, 268-302.

3. Balconi M, Pozzoli U. (2005) Comprehending semantic and grammatical violations in Italian N400 and P600 comparison with visual and auditory stimuli. J Psycholinguist Res 34, 71-98.

4. Birdsong D, Molis M. (2001) On the evidence for maturational constraints in second-language acquisition. J Mem Lang 44, $235-$ 249.

5. Cahill JM, Polich J. (1992) P300, probability, and introverted/extroverted personality types. Biol Psychol 33, 23-35.

6. Coulson S, King JV, Kutas, M. (1998) Expect the unexpected: Event-related brain response to morphosyntactic violations Lang Cogn Proc 13, 21-58.

7. De Diego Balaguer R, Sebastian-Galles N, Diaz B, RodriguezFornells A. (2005) Morphological processing in early bilinguals an ERP study of regular and irregular verb processing. Cogn Brain Res 25, 312-327.

8. Doucet C, Stelmack RM. (2000) An event-related potential analysis of extraversion and individual differences in cognitive processing speed and response execution. J Pers Soc Psychol 78, 956-964.

9. Elston-Güttler KE, Friederici AD. (2005) Native and L2 processing of homonyms in sentential context. J Mem Lang 52, 256-283.

10. Friederici AD. (1995) The time course of syntactic activation during language processing: a model based on neuropsychological and neurophysiological data. Brain Lang 50, 259-281.

11. Friederici AD, Mecklinger A. (1996) Syntactic parsing as revealed by brain response: First pass and second-pass parsing processes. $\mathrm{J}$ Psycholinguist Res 25, 157-176.

12. Friederici AD, Hahne A, Mecklinger A. (1996) Temporal structure of syntactic parsing: early and late event-related brain potential effects. J Exp Psychol Lear Mem Cogn 22, 1219-1248.

13. Friederici AD, Gunter TC, Hahne A, Mauth K. (2004) The relative timing of syntactic and semantic processes in sentence comprehension. Neuroreport 15, 165-169.

14. Frisch S, Schlesewsky M. (2001) The N400 reflects problems of thematic hierarchizing Neuroreport 12, 3391-3394.

15. Frisch S, beim Graben P. (2005) Finding needles in haystacks: Symbolic resonance analysis of event-related potentials unveils different processing demands Cogn Brain Res 24, 476-491.

16. Gunter TC, Jackson JL, Mulder G. (1992) An electrophysiological study of semantic processing in young and middle-aged academics. Psychophysiology 29, 38-54.

17. Gunter TC, Friederici AD. (1999) Concerning the automaticity of syntactic processing Psychophysiology 36, 126-137.

18. Gunter TC, Friederici AD, Hahne A. (1999) Brain responses during sentence reading: visual input affects central processes Neuroreport 10, 3175-3178.

19. Hagoort P. (2003) Interplay between syntax and semantics during sentence comprehension: ERP effects of combining syntactic and semantic violations. J Cogn Neurosci 15, 883-899.

20. Hagoort P, Brown C, Groothusen J. (1993) The syntactic positive shift (SPS) as an ERP measure of syntactic processing. Lang Cogn Proc 8, 439-483.

21. Hagoort P, Brown CM. (1999) Gender electrified: ERP evidence on the syntactic nature of gender processing. J Psycholinguist Res 28, 715-728

22. Hahne A. (2001) What's different in second-language processing? Evidence from event-related brain potentials. J Psycholinguist Res 30, 251-266

23. Hahne A, Friederici AD. (1999) Electrophysiological evidence for two steps in syntactic analysis. Early automatic and late controlled processes. J Cogn Neurosci 11, 194-205.

24. Hahne A, Friederici AD. (2002) Differential task effects on semantic and syntactic processes as revealed by ERPs. Cogn Brain Res 13, 339-356.

25. Hoen M, Dominey PF. (2000) ERP analysis of cognitive sequencing: a left anterior negativity related to structural transformation processing. Neuroreport 11, 3187-3191.

26. Hohlfeld A, Mierke K, Sommer W. (2004) Is word perception in a second language more vulnerable than in one's native language?
Evidence from brain potentials in a dual task setting. Brain Lang 89, 569-579.

27. Johnson J, Newport E. (1989) Critical period effects in second language learning: the influence of maturational state on the acquisition of English as a second language. Cogn Psychol 21, 60-99.

28. Kessler K. (2004) ERP correlates of word order and morphosyntactic phenomena in adult native speakers and second language learners of English. Dissertation Abstracts International, Section A: The Humanities and Social Sciences 64, 2863

29. Kollárik T, Poliaková E, Ritomský A. Freiburg Personality Inventory (in Slovak). Bratislava: Psychodiagnostické a didaktické testy, 1984.

30. Kotz SA, Elston-Güttler K. (2004) The role of proficiency on processing categorical and associative information in the L2 as revealed by reaction times and event-related brain potentials. $\mathrm{J}$ Neurolinguist 17, 215-235.

31. Kuperberg GR, Sitnikova T, Caplan D, Holcomb PJ. (2003) Electrophysiological distinctions in processing conceptual relationships within simple sentences. Cogn Brain Res 17, 117-129.

32. Kuperberg GR, Sitnikova T, Caplan D, Holcomb PJ. (2003) Linguistic stimuli. http://neurocog.psy.tufts.edu/animacyMaterials.htm

33. Kutas M, Hillyard SA. (1980) Reading senseless sentences: brain potentials reflect semantic incongruity. Science 207, 203-205.

34. Kutas M, Hillyard SA. (1984) Brain potentials during reading reflect word expectancy and semantic association. Nature 307, $161-163$.

35. Kutas M, Van Petten C, Besson M. (1988) Event-related potential asymmetries during the reading of sentences. Electroencephalog Clin Neurophysiol 69, 218-233.

36. Moreno EM, Kutas M. (2005) Processing semantic anomalies in two languages: an electrophysiological exploration in both languages of Spanish-English bilinguals. Cogn Brain Res 22, 205-220.

37. Mueller JL, Hahne A, Fujii Y, Friederici AD. (2005) Native and nonnative speakers' processing of a miniature version of Japanese as revealed by ERPs. J Cogn Neurosci 17, 1229-1244.

38. Neville HJ, Nicol JL, Barss A, Foerster KI, Garrett MF. (1991) Syntactically based sentence processing classes: Evidence from event-related brain potentials. J Cogn Nurosci 3, 151-165.

39. Osterhout L, Holcomb PJ, Swinney DA. (1994) Brain potentials elicited by garden-path sentences: evidence of the application of verb information during parsing. J Exp Psychol Learn Mem Cogn 20, 786-803.

40. Petřek J. (2004) ERPs to words - effect of gender and site of recording electrode. Biomed Pap Med Fac Univ Palacky Olomouc Czech Rep 148, 145-152.

41. Petřek J. (2004) ERPs to nouns and verbs - congruences and differences. Biomed Pap Med Fac Univ Palacky Olomouc Czech Rep 148, 153-156.

42. Petřek J. (2004) ERPs to subclasses of nouns and verbs. Biomed Pap Med Fac Univ Palacky Olomouc Czech Rep 148, 157-160.

43. Petřek J. (2005a) Noun-verb decision time - variability sources. Homeostasis Health Dis 43, 113-120.

44. Petřek J. (2005) Some variability sources of event related potentials to word stimuli. Homeostasis Health Dis 43, 121-127.

45. Phillips NA, Segalowitz N, O’Brien I, Yamasaki N. (2004) Semantic priming in a first and second language: evidence from reaction time variability and event-related brain potentials $\mathrm{J}$ Neurolinguistics 17 , 237-262.

46. Polich J, Martin S. (1992) P300, cognitive capability, and personality: A correlational study of university undergraduates. Pers Indiv Dif 13, 533-543.

47. Polich J, Kok A. (1995) Cognitive and biological determinants of P300: an integrative review. Biol Psychol 41, 103-146.

48. Posada A, Vianin P, Giard MH, Franck N. (2003) Stimulus and response ERP analyses of a two-level reaction time task. Exp Brain Res 152, 79-86.

49. Proverbio AM, Čok B, Zani A. (2002) Electrophysiological measures of language processing in bilinguals. J Cogn Neurosci 14 , 994-1017.

50. Sanders LD, Neville HJ. (2003) An ERP study of continuous 
speech processing: I Segmentation, semantics, and syntax in native speakers. Cogn Brain Res 15, 228-240.

51. Sanders LD, Neville HJ. (2003) An ERP study of continuous speech processing: II Segmentation, semantics, and syntax in nonnative speakers Cogn Brain Res 15, 214-227.

52. Stelmack RM, Houlihan M, McGarry-Roberts PA. (1993) Personality, reaction time, and event-related potentials. J Pers Soc Psychol 65, 399-409.
53. The Common European Framework in its political and educational context. http://culture2.coe.int/portfolio//documents/ 0521803136txt.pdf

54. Weber-Fox CM, Seville HJ. (1996) Maturational constraints on functional specialization for language processing: ERP and behavioral evidence in bilingual speakers. J. Cogn Neurosci 8, 231-236.

55. Weckerly J, Kutas M. (1999) An electrophysiological analysis of animacy effects in the processing of object relative sentences. Psychophysiology 36, 559-570. 